\title{
REDESCRIPTIONS OF THREE SPECIES OF THE GENUS NEOBISIUM FROM THE BALKANS AND THE CARPATHIANS (ARACHNIDA: PSEUDOSCORPIONES)
}

\author{
JÁnos Novák ${ }^{1}$ and Christoph HöRweg ${ }^{2}$ \\ ${ }^{1}$ Eötvös Loránd University, Department of Systematic Zoology and Ecology \\ H-1117 Budapest, Pázmány Péter sétány 1/C, Hungary; E-mail: novakjanos01@gmail.com \\ ${ }^{2}$ Natural History Museum Vienna, 3. Zoology (Invertebrates) \\ Burgring 7, 1010 Vienna, Austria; E-mail: christoph.hoerweg@nhm-wien.ac.at
}

Redescriptions of Neobisium (Neobisium) polonicum Rafalski, 1937, N. (N.) bosnicum Beier, 1939 and N. (N.) bosnicum herzegovinense Beier, 1939 are given, accompanied with new illustrations of the most important morphological characters. N. (N.) bosnicum herzegovinense Beier, 1939 is elevated to species rank as Neobisium (N.) herzegovinense, Beier, 1939. N. (N.) biharicum Beier, 1939 is proposed as a junior subjective synonym of $N$. (N.) polonicum. New records of $N$. (N.) polonicum from Romania are presented.

Keywords: pseudoscorpions, Neobisiidae, taxonomy, synonymy, new records.

\section{INTRODUCTION}

The pseudoscorpion genus Neobisium J. C. Chamberlin, 1930 including more than 230 epigean and hypogean species is one of the most diverse genera of the order. The genus has a predominantly European and Mediterranean distribution, with some species extending Eastwards across the Southwestern part of Asia to India (Harvey 2013). The identification of the species often proves to be a difficult task, as since Beier's book (BEIER 1963) no comprehensive key was worked out for the Neobisium species. However, recently some relevant keys were elaborated for the pseudoscorpion fauna of different specific regions of Middle Europe, which are extraordinarily useful but are restricted for the fauna of specific countries (DeVore-Scribante 1999, Mahnert 2004, Christophoryoví et al. 2011).

The identification of members of the genus from the Eastern and Southern Carpathians and from the Balkans unavoidably meets difficulties since Beier's book (BEIER 1963) often uses outdated and sometimes questionable chracters (e.g. a narrow range of morphometric characters, number of setae on cheliceral hand) in case of Neobisium species. Furthermore, in case of many species from these regions we have old descriptions without drawings nor mentioning of some recently used morphological characteristics. 
Neobisium polonicum Rafalski, 1937 was described from localities in the Northeastern Carpathians (now in Ukraine) (RAFALsKi 1937), and later was found also in Romania (HADžI 1939) and Slovakia (KRUMPÁL 1979); both of the authors gave some complementary data to the morphological and morphometric characteristics of the species.

Neobisium biharicum Beier, 1939 was described from several localities in the Western Transylvanian Mts (BEIER 1939a), and later was also reported from the Northeastern Carpathians (Gyertyánliget, Máramaros, Ukraine) (Szent-IvánY 1941), from the Eastern Carpathians (Lepşa Valley, Romania) (Dumitrescu 1976), from the Movile Cave in southern Dobrogea (Romania) (ĆuRčrć et al. 1993) and from Hungary (Macskabarlang Cave, Pilis Mts) (NovÁк 2013).

The areas of these two very similar species significantly overlap, however, apart from Beier's book (BEIER 1963) there was no comprehensive comparison published on N. polonicum and N. biharicum.

Neobisium bosnicum Beier, 1939 was described from Bosnia and Herzegovina (BEIER 1939b), and no further records of the species was published after, except the description of a new subspecies, Neobisium bosnicum ondriasi Mahnert, 1973 from Greece (MAHNERT 1973).

Neobisium (N.) bosnicum herzegovinense Beier, 1939 was described in the same publication of Beier as N. (N.) herzegovinense Beier, 1939 from Bosnia and Herzegovina, but later he listed this taxon as a subspecies of N. bosnicum (BEIER 1963).

The aim of this work is to update our knowledge regarding the above mentioned species of Neobisium, providing modern redescriptions with new figures of their important morphological characteristics.

\section{MATERIAL AND METHODS}

The type specimens examined are housed in the Naturhistorisches Museum Wien, Vienna (NHMW); additional material of N. polonicum is deposited at the Hungarian Natural History Museum, Budapest (HNHM). We follow the terminology of CHAMbERLIN (1931), Harvey (1992) and Judson (2007). Samples are preserved in 70\% ethanol. The material was examined by using a stereomicroscope and light microscope; the specimens were cleared in lactic acid. Drawings were made with the aid of a Zeiss Axioskop 2 microscope. Measurements were carried out by the use of Olympus Soft Imaging analySIS work 5.0 software.

\section{RESULTS \\ Neobisium (Neobisium) polonicum Rafalski, 1937 \\ (Figs 1A-E, 2A-D, 3A-E)}

Neobisium (Neobisium) polonicum Rafalski, 1937: 1-14, figs 1-3.

Neobisium (Neobisium) biharicum Beier, 1939a: 10-14, figs 6-8. syn. nov. 
Type material examined. Neobisium (N.) polonicum (syntypes): 1 §, 2 , Ukraine, near to Kosiv, Ardan Wyzny Valley, 30.07.1934, leg: Jan Rafalski (NHMW-26667).

Neobisium (N.) biharicum (syntypes): 201,5 ㅇ, Romania, Transylvania, Turda (Torda), Câmpeni (Topánfalva), 20.07.1938, leg: Robert Leruth (NHMW-25226).

Other material examined. $1 \delta^{\Uparrow}$, Romania, Tihău (Tihó), Almás Valley, County Sălaj (Szilágy), 11.05.2015, leg: Aranka Grabant, Ottó Merkl, Viktória Szőke (HNHM Pseud-1203); 1 +, Romania, Tusa (Tuszatelke), County Sălaj (Szilágy), Ponor, 752m, edge of beech forest and pasture with spring and stream, 02.10.2014, leg: Zsolt Bálint, Dávid Murányi, Gergő Katona, László Dányi (HNHM Pseud-1153); 1 +, Romania, Tusa (Tuszatelke), County Sălaj (Szilágy), valley of the Barcăului stream (Berettyó), edge of beech forest and pasture with spring and stream, 02.10.2014, leg: Z. Bálint, D. Murányi, G. Katona, L. Dányi (HNHM Pseud-1154); 2 ô, 1 우, Romania, Iaz (Krasznajáz), County Sălaj (Szilágy), valley of the Iaz Stream, beech forest, 30.09.2014, leg: Z. Bálint, D. Murányi, G. Katona, L. Dányi (HNHM Pseud-1155); 1 đ̂, Romania, Băile Borșa (Borsabánya), County Maramureș (Máramaros), 22-26.04.1941, leg. Zoltán Kaszab \& Jenő Fodor, det: József Szent-Ivány (confirmed by Max Beier); 1 ㅇ, Romania, Cluj-Napoca (Kolozsvár), Valley Plecska, 10.03.2014, leg: LeventePéter Kolcsár; 2 ô, Romania, Răchițele (Havasrekettye), from cave, County Cluj (Kolozs), 07.2008 (HNHM Pseud-1873); 2 §̊, Romania, Szenéte, County Hargita, 14.05.2014, leg: J. Novák (HNHM Pseud-1814); 1 đ̊, Romania, Kalotaszentkirály, Háromkő Mount, County Cluj (Kolozs), 19.04.2014, leg: J. Novák \& Tímea Szederjesi (HNHM Pseud-1875).

Description. Large-sized pseudoscorpion with epigean habitus. Carapace, chelicerae and pedipalps reddish brown, opisthosoma and legs yellowish. Measurements and ratios of the studied specimens as in Tables 1-2.

Carapace approximately as long as broad, surface smooth (Figs 1A, 1B). Epistome triangular and prominent. Two pair of eyes with lens. Two pairs of slitlike lyrifissures at anterior part of carapace. Normally 1, in some cases also 2 or 3 preocular setae on each side. Setal formula: 4:6-10:6-8:5-7 (21-26).

Coxal area. Manducatory process with normally 5 setae (exceptionally with 6 ), rest of pedipalpal coxae with 10-15 setae; pedal coxa I with 11-15 setae; II: 9-14; III: 7-14; IV: 10-19. Anterolateral process of coxa I long, triangular and apically pointed; medial process prominent, with denticles.

Opisthosoma with granulostriate pleural membrane. Chaetotaxy of tergites I-X: 6-8:6-8:6-10:9-10:6-10:8-10:8-12:8-12: 8-10:8-10. Segment XI with 18 setae, 6 of them tactile. Anal cone with 2 ventral and 2 dorsal setae. Male genital region: sternite II with 15-20 small setae, sternite III with $41-48$ setae, of which $15-22$ along posterior margin. Normally $6+6$ internal setae in male opening (in one of the specimens $5+6$ and in an other one 9+8 was observed). Medial genital sack elongated and band-like, extending over the middle of the ophistosoma. Female genital region: sternite II with 11-25 small setae, sternite III with 17-35 small setae in a row. Chaetotaxy of sternites IV-X: 12-20:14-18:14-20:13-18:1419:10-18:11-18.

Chelicera (Figs 1C-E) with usually 7-8 setae on hand, rarely with 6 or 9. Number of these setae can show different values on the two chelicerae of a single specimen. Subgaleal seta $0.62-0.69 \times$ from base of movable finger. Spinneret a prominent hyaline tubercle with 9-17 silk ducts. Fixed finger with 11-17 small and medium-sized teeth, movable finger with 9-14 small and medium-sized teeth, and one large tooth in the middle, which can be secondarily toothed. Rallum with 8 blades, two distalmost blades unilaterally pinnate on anterior face. The distalmost blade with enlarged basis and separated from the proceeding one. Serrula exterior with 32-40 blades, serrula interior with 32-36 blades. 


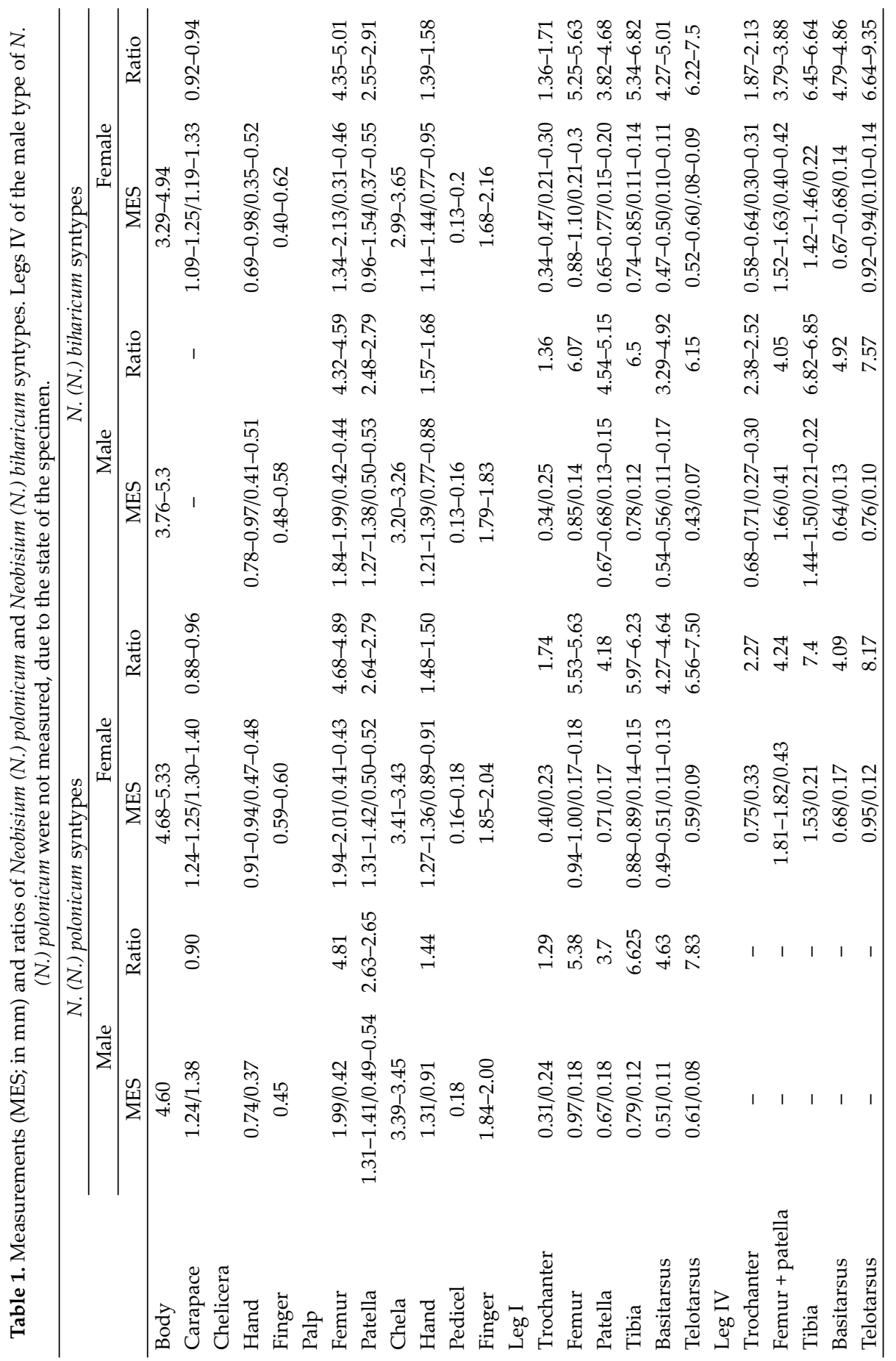


Pedipalp (Figs 2A-D) surfaces smooth. Trochanter with tubercle. Femur 4.23-5.19, patella 2.44-3.39 times as long as broad. Chela (Figs 3A, B, E) slender and markedly curved. Pedicel bears 10-15 dorsal micropores. Chelal fingers 1.27-1.41 times longer than hand with pedicel. Fixed chelal finger with 95-110 close-set teeth of unequal length (Figs 3C-D); on the distal half of the finger 1-9 normal sized teeth between two larger. However, the difference between the normal and larger teeth is not conspicuous in all case. Movable chelal finger with 75-95 teeth (the distal one-fourth of the dental line with conical teeth, the others becoming flattened towards the finger base), dental line ending at the level of trichobothrium $b$. Trichobothria of chelal fingers distributed as in Figures 3A, B, E. Distance between trichobothria $i b$ and ist 3.6-5.2 times as long as between ist and it.
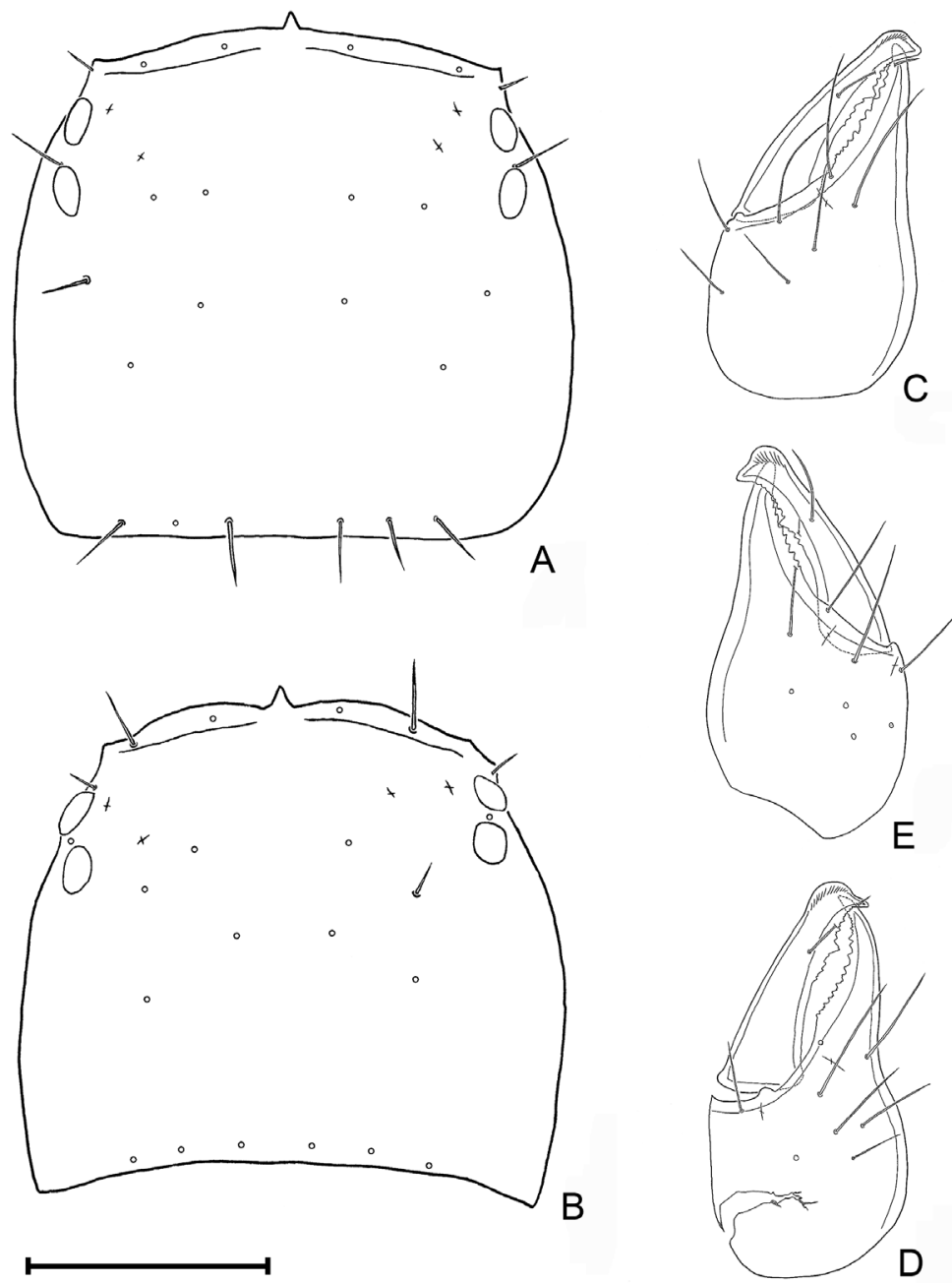

Fig. 1. Neobisium (N.) polonicum: $\mathrm{A}=$ carapace of female syntype, $\mathrm{B}=$ carapace, male (HNHM Pseud-1874), C = left chelicera, female syntype, D = left chelicera, male (HNHM Pseud-1874); E = right chelicera of $N$. biharicum male, syntype. Scale bar: $0.5 \mathrm{~mm}$ 
Table 2. Measurements (in $\mathrm{mm}$ ) and ratios of the investigated additional Neobisium (N.) polonicum material.

\begin{tabular}{|c|c|c|c|c|}
\hline & \multicolumn{2}{|l|}{ Male } & \multicolumn{2}{|c|}{ Female } \\
\hline & Measurements & Ratio & Measurements & Ratio \\
\hline Body & $4.45-5.02$ & & $4.53-5.11$ & \\
\hline Carapace & $1.12-1.27 / 1.22-1.35$ & $0.92-0.94$ & $1.17-1.24 / 1.21-1.38$ & $0.90-0.96$ \\
\hline \multicolumn{5}{|l|}{ Chelicera } \\
\hline Hand & $0.74-0.85 / 0.39-0.50$ & & $0.76-0.99 / 0.36-0.48$ & \\
\hline Finger & $0.47-0.57$ & & $0.44-0.61$ & \\
\hline \multicolumn{5}{|l|}{ Palp } \\
\hline Femur & $1.32-1.99 / 0.33-0.46$ & $4.35-5.19$ & $1.86-1.95 / 0.41-0.50$ & $4.46-4.61$ \\
\hline Patella & $1.09-1.62 / 0.33-0.52$ & $2.53-3.39$ & $1.19-1.36 / 0.41-0.52$ & $2.44-2.88$ \\
\hline Chela & $2.99-3.38$ & & $3.21-3.36$ & \\
\hline Hand & $1.15-1.33 / 0.76-0.81$ & $1.43-1.73$ & $1.25-1.35 / 0.79-0.94$ & $1.42-1.58$ \\
\hline Pedicel & $0.12-0.19$ & & $0.13-0.19$ & \\
\hline Finger & $1.69-1.96$ & & $1.68-1.90$ & \\
\hline \multicolumn{5}{|l|}{ Leg I } \\
\hline Trochanter & $0.32-0.37 / 0.21-0.24$ & $1.33-1.54$ & $0.32-0.46 / 0.23-0.29$ & $1.38-1.64$ \\
\hline Femur & $0.81-0.97 / 0.15-0.19$ & $5.11-5.32$ & $0.94-1.04 / 0.16-0.24$ & $5.11-6.18$ \\
\hline Patella & $0.64-0.70 / 0.15-0.17$ & $4.11-4.64$ & $0.69-0.75 / 0.14-0.19$ & $3.95-4.84$ \\
\hline Tibia & $0.76-0.91 / 0.12-15$ & $6.08-6.34$ & $0.75-0.81 / 0.11-0.15$ & $5.43-6.82$ \\
\hline Basitarsus & $0.44-0.52 / 0.09-0.11$ & $4.48-4.85$ & $0.49-0.52 / 0.09-0.12$ & $4.33-5.44$ \\
\hline Telotarsus & $0.54-0.55 / 0.06-0.07$ & $7.72-7-86$ & $0.55-0.62 / 0.09$ & $6.32-6.95$ \\
\hline \multicolumn{5}{|l|}{ Leg IV } \\
\hline Trochanter & $0.51-0.62 / 0.26-0.30$ & $1.96-2.44$ & $0.56-0.64 / 0.29-0.32$ & $1.93-2.31$ \\
\hline Femur+patella & $1.43-1.62 / 0.28-0.43$ & $3.76-5.11$ & $1.58-1.76 / 0.40-0.42$ & $3.95-4.19$ \\
\hline Tibia & $1.30-1.46 / 0.16-0.23$ & $6.34-8.13$ & $1.44-1.54 / 0.21-0.22$ & $6.68-7.11$ \\
\hline Basitarsus & $0.60-0.68 / 0.12-0.15$ & $4.51-5.0$ & $0.65-0.67 / 0.14-0.16$ & $4.19-4.68$ \\
\hline Telotarsus & $0.70-0.79 / 0.08-0.13$ & $6.07-8.77$ & $0.81-0.93 / 0.09-0.14$ & $6.62-9.02$ \\
\hline
\end{tabular}

Legs with smooth surfaces. Claws smooth and simple, arolia shorter than claws on all legs. Subterminal seta of telotarsus IV with two serrate rami. Tactile setae present on tibia, basitarsus and telotarsus of leg IV.

Remarks. N. polonicum was described from a male and a female type and from numerous paratypes collected in the Eastern part of the Northwestern Carpathians, from 20 localities between the area of the Cheremosh and San rivers, in Ukraine (RAFALSKI 1937). The types and the majority of the para- 
types are supposed to be stored in Rafalski's collection at the Adam Mickiewicz University, Poznan (Poland), which is not catalogued yet and could not be investigated. However, some syntypes (3 ex. labelled as paratypes) are deposited in the Arachnida Collection of the NHMW, Vienna (Austria). The locality of this sample could not be found unambiguously amongst the type localities in the original description, but it was collected by J. Rafalski in 1934 at the same region, and it is labelled as "paratypes". Thus, it is not clear, if they really represent a part of the type material, but they are clearly conspecific with it.

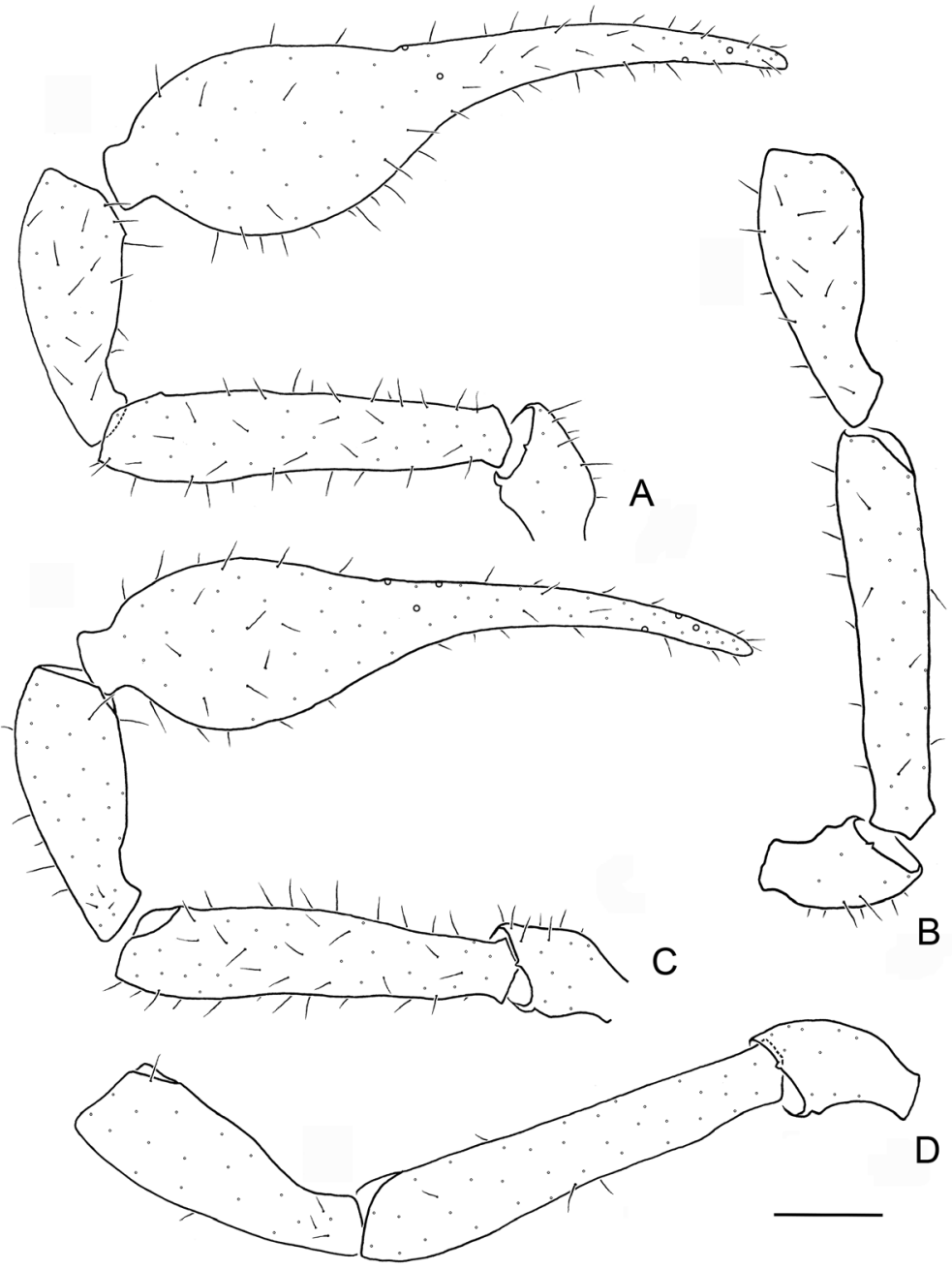

Fig. 2. Neobisium (N.) polonicum, syntype: $\mathrm{A}=$ left pedipalp, female, $\mathrm{B}=$ left pedipalp, male; $\mathrm{C}-\mathrm{D}=\mathrm{N}$. biharicum, syntype, left pedipalp: $\mathrm{C}=$ male, $\mathrm{D}=$ female. Scale bar: $0.5 \mathrm{~mm}$ 
The species later was recorded by HaDžI (1939) also in Romania, in the Western Transylvanian Mts, which is the type locality of N. biharicum, with complementary information to the characteristics of the species. In 1979 the species was found in Slovakia as well (KRUMPÁL 1979).

$N$. biharicum was described from several locations of the Western Transylvanian Mts (BeIER 1939a), on the basis of numerous syntypes. Seven of them are located in the NHMW and could be investigated within this study. The rest of the material are deposited in the Royal Belgian Institute of Natural Sciences (Brussels, Belgium).

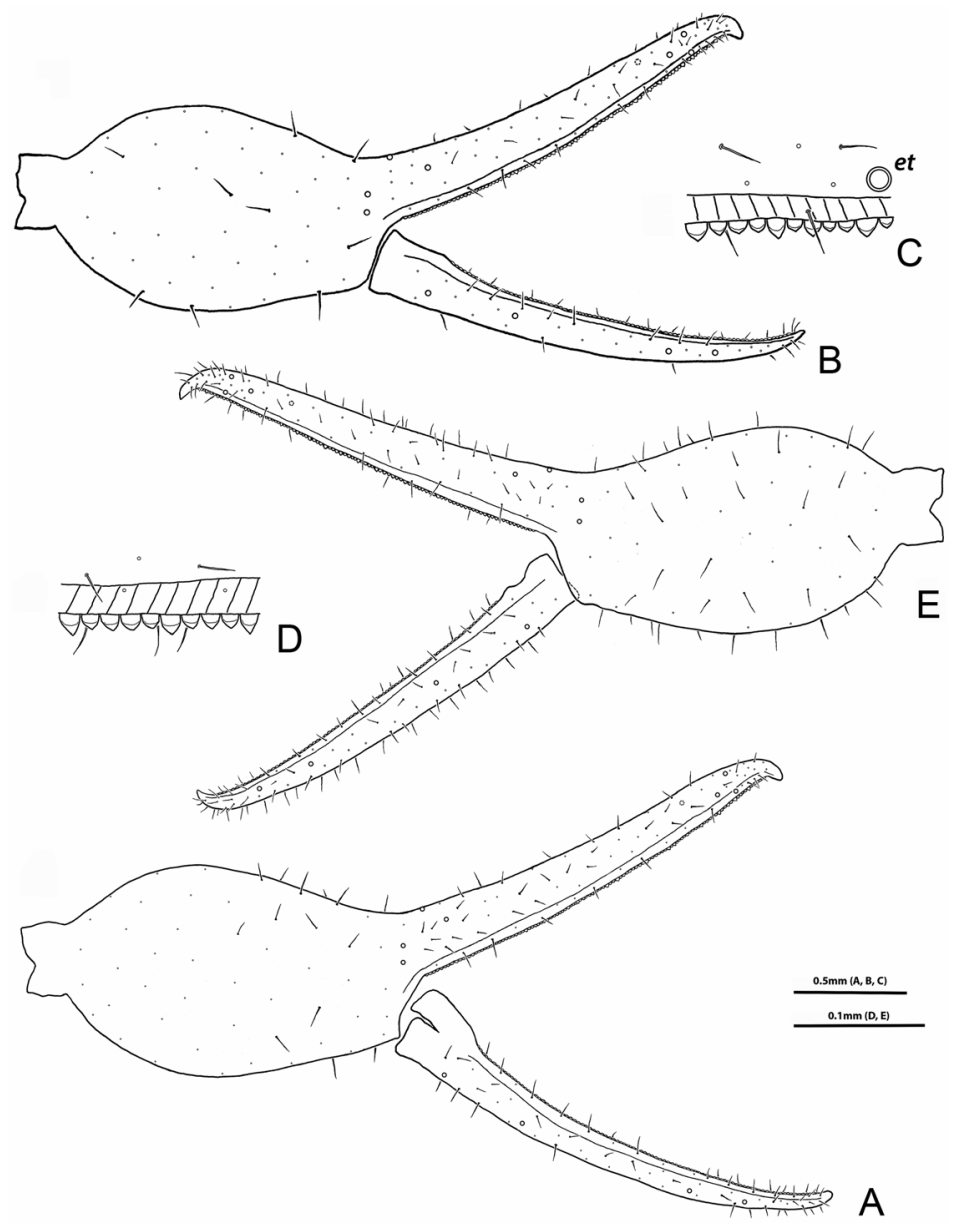

Fig. 3. Neobisium (N.) polonicum: A = left chela, female (HNHM Pseud-1153), B = right chela, male syntype, $\mathrm{C}=$ chelal teeth of fixed finger at the level of $e t$, male (HNHM Pseud-1873); $\mathrm{D}-\mathrm{E}=\mathrm{N}$. biharicum, male, syntype: $\mathrm{D}=$ chelal teeth of fixed finger at the level of $i s t, \mathrm{E}$ : right chela 
The species was later reported from the Northeastern Carpathians (Gyertyánliget, Máramaros, Ukraine) (Szent-IvánY 1941), from the Lepşa Valley in the Eastern Carpathians, Romania (Dumitrescu 1976), from the Movile Cave in southern Dobrogea, Romania (Ćurčıć et al. 1993) and from the Pilis Mts, Hungary (NovÁк 2013).

The specimen found in the Northeastern Carpathians by Szent-Ivány and confirmed by Beier as N. biharicum was also studied, together with some further specimens from the collection of the HNHM. Additional exemplars were collected by the first author in 2014 and by the research team of the HNHM in 2014-2015; this material was also investigated.

In the former literature these two species were distinguished by the number of setae on the cheliceral palm (respectively 7 at $N$. polonicum and 8 at $N$. biharicum), the dentition of the fixed chelal finger and morphometrical ratios, chiefly the ratio of palpal femur (4.9-5.2 at N. polonicum and 4.6-4.8 at N. biharicum) (BEIER 1963).

The delimitation of N. polonicum and N. biharicum by using the number of setae on the cheliceral palm can be misleading, as even in the original description of N. biharicum it is mentioned that some specimens have 7 such setae in contrast with the usual 8. Furthermore, now it is obvious, that in case of Neobisium species the number of these setae has a larger intraspecific variation than it was assumed before (Novék 2014).

The dentition of fixed chelal finger of $N$. polonicum was described as teeth with unequal length, usually 2-4 smaller teeth between two somewhat larger; however, the difference between the smaller and larger teeth is not conspicuous. In case of $N$. biharicum we can find in the description, that some isolated larger teeth are situated in the line of normal teeth (RAFALSKI 1937, BeIER 1939a, 1963). In our opinion these two descriptions are unsufficient for an unambiguous delimitation, and cover the same pattern.

Using the morphometric ratios of the palpal femora for delimitation of N. polonicum and N. biharicum can also be misleading. Whilst studying N. polonicum and N. biharicum type and non type material it has been revealed, that their morphometrical values overlap. It shows a somewhat wider range of femoral morphometrical ratio values (4.32-5.19) than in the earlier literature. This is not an unique characteristic within the family Neobisiidae: in case of some other Neobisium species similar wide ranges were documented (N. dolomiticum: $4.8-5.5 ;$ N. jugorum: 4.0-5.5; N. schenkeli: 5-5.7) (DeVore-Scribante 1999).

Taking the above mentioned morphological observations into consideration and the fact that the area of N. polonicum and N. biharicum obviously overlap, the authors of this paper propose $N$. biharicum to be a junior subjective synonym of $N$. polonicum. 


\section{Neobisium (Neobisium) bosnicum Beier, 1939 (Figs 4A-F)}

Type material examined (syntypes): $1 \hat{\delta}, 2$, Bosnia and Herzegovina, Bjelašnica Planina, cleave cave, southeast to Sarajevo, $2067 \mathrm{~m}$ asl., 29.06.1912 (NHMW-25213); 3 $\hat{\text {, }}, 2$ 9 , Bosnia and Herzegovina, from caves of the Bjelašnica Mts, 1918 (NHMW-25214); 1 ठ, 1 , Bosnia and Herzegovina, Vran Planina, west to Narenta, under stones, 1922 (NHMW25215).

Description. Medium-sized pseudoscorpion with epigean habitus. Carapace and tergites olivebrown, pedipalps reddish-brown, other parts of opisthosoma and legs yellowish. Measurements and ratios of the studied specimens as in Table 3.

Carapace longer than broad, surface smooth (Fig. 4A). Epistome triangular and prominent. Two pairs of well developed eyes with lens. One pair of slitlike lyrifissures at anterior and two pairs at posterior half of carapace. Preocular setae absent. Setal formula: 4:6:6-10:8-14 (26-34).

Coxal area. Manducatory process with 5-6 setae, rest of pedipalpal coxa with 9-14 setae; pedal coxa I with 10-13 setae; II: 7-14; III: 6-11; IV: 13-17. Anterolateral process of coxa I long, triangular and apically pointed; medial process round and flattened and dentate.

Opisthosoma with granulostriate pleural membrane. Chaetotaxy of tergites I-X: 8-10:8-16:10-14:12-20:14-20:14-18:12-18:12-16:10-16:10-14. Segment XI with 14-22 setae, 6 of them tactile. Anal cone with 2 ventral and 2 dorsal setae. Male genital region: sternite II with 6-13 small setae, sternite III with 24-28 setae, of which 12-15 along posterior margin. In male opening $4+4$ internal setae. Medial genital sack could not be clearly observed. Female genital region: sternite II with 7-12 small setae, sternite III with 10-14 small setae in a row. Chaetotaxy of sternites IV-X: 15-23:14-26:16-26:14-18:17-22:16-20:17-20.

Chelicera with 6-8 setae on hand (Fig. $4 \mathrm{~B}$ ), this number can vary between the chelicerae of the same exemplar. Subgaleal seta $0.59-0.65 \times$ from base of movable finger. Spinneret a flattened hyaline tubercle with 10-14 silk ducts. Fixed finger with 11-15 small teeth, movable finger with 8-10 small and medium-sized teeth. Rallum with 8 blades, two distalmost blades unilaterally pinnate on anterior face. The distalmost blade with enlarged basis and separated from the proceeding one. Serrula exterior with 24-28 blades, serrula interior with 22-26 blades.

Pedipalp (Fig. 4C) surfaces smooth. Trochanter with tubercle. Femur 3.58-3.75, patella 2.28-2.50 times as long as broad. Patella with 3 greater lyrifissures on basal part and 2 smaller near the articulation with the hand. Pedicel of patella bears $2-4$ micropores. Chela (Fig. 4D). Pedicel bears 3-4 dorsal micropores. Chelal fingers approximately as long as hand with pedicel. Fixed chelal finger with 55-63 close-set and pointed teeth of equal length (Figs 4E-F). Movable chelal finger with 49-54 rounded teeth, dental line ending between the level of trichobothria $s b$ and $b$. Trichobothria of chelal fingers distributed as in Fig. 4D. Distance between trichobothria $i b$ and ist approximately as long as between ist and it.

Legs with smooth surfaces. Claws smooth and simple, arolia shorter than claws on all legs. Subterminal seta of telotarsus IV with two rami. Tactile setae present on tibia, basitarsus and telotarsus of leg IV. 


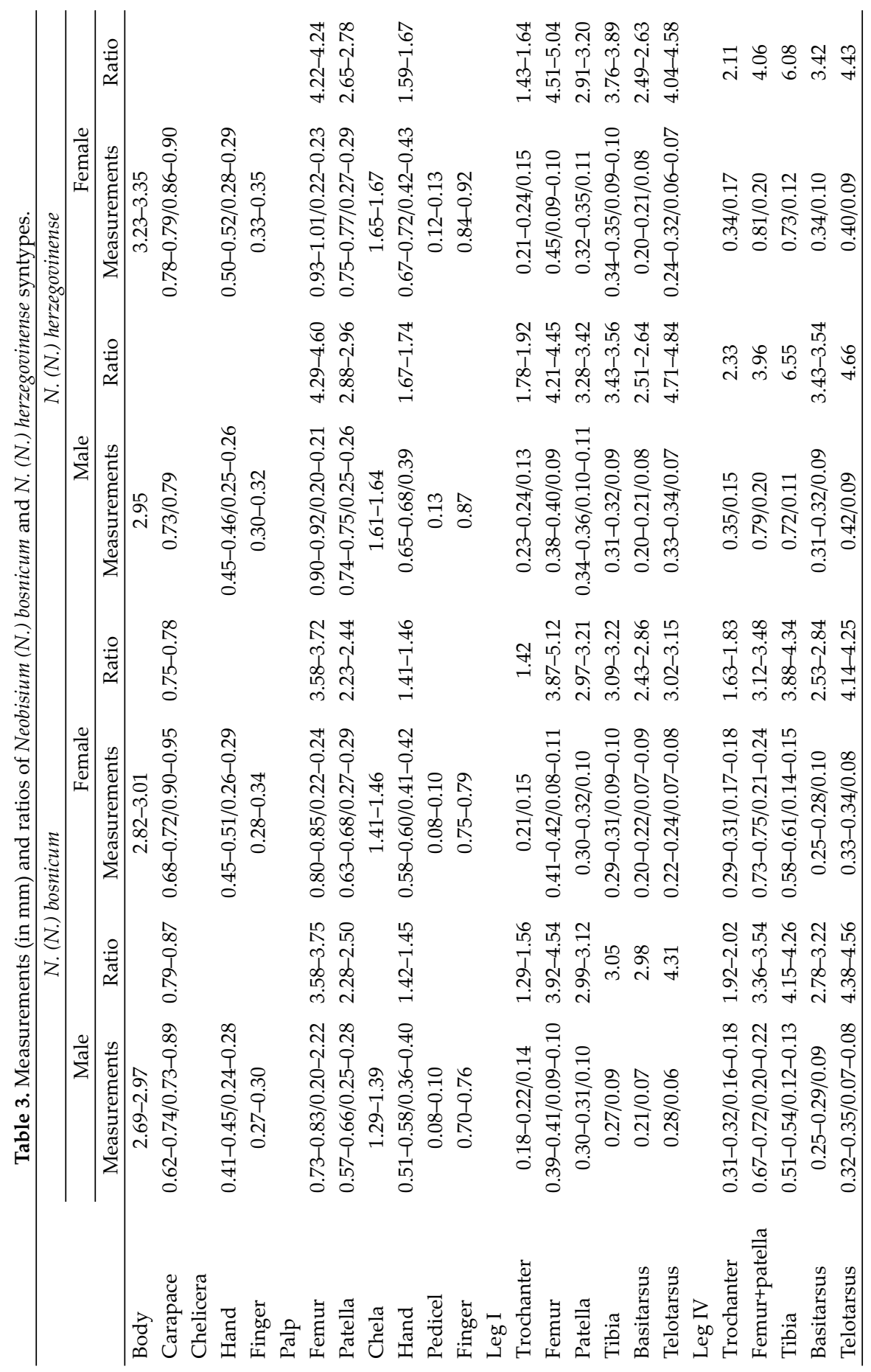


Remarks. N. bosnicum was described by Beier from 4 male, 6 female and 1 juvenile syntypes, from three different localities in Bosnia and Herzegovina (BeIer 1939b). In 1973 a new subspecies, N. bosnicum ondriasi was described
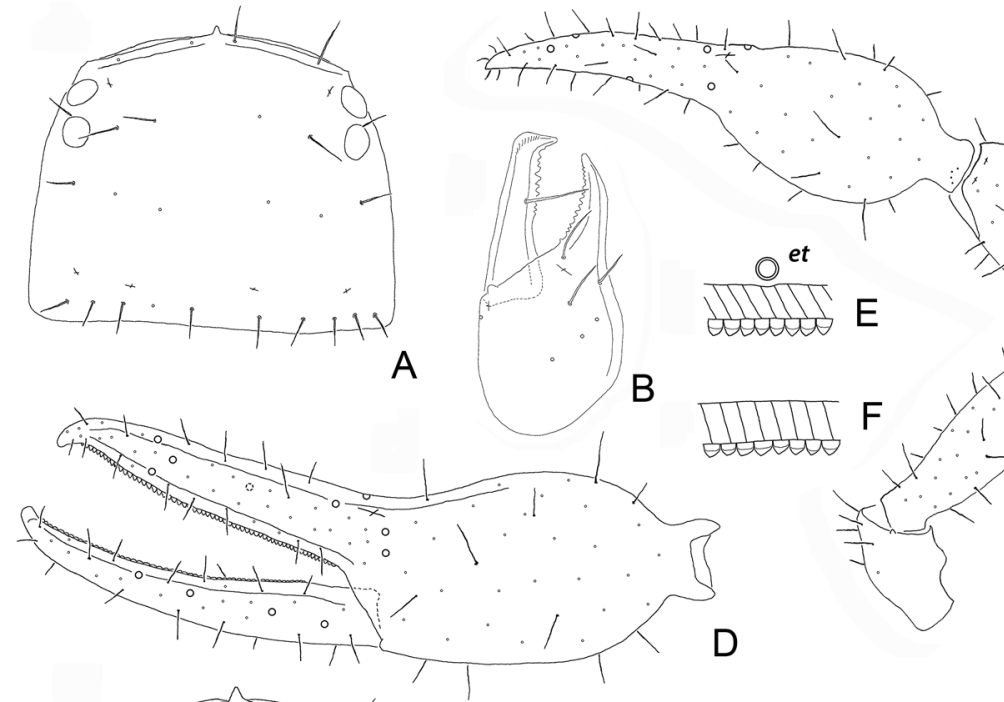

$\mathrm{D}$
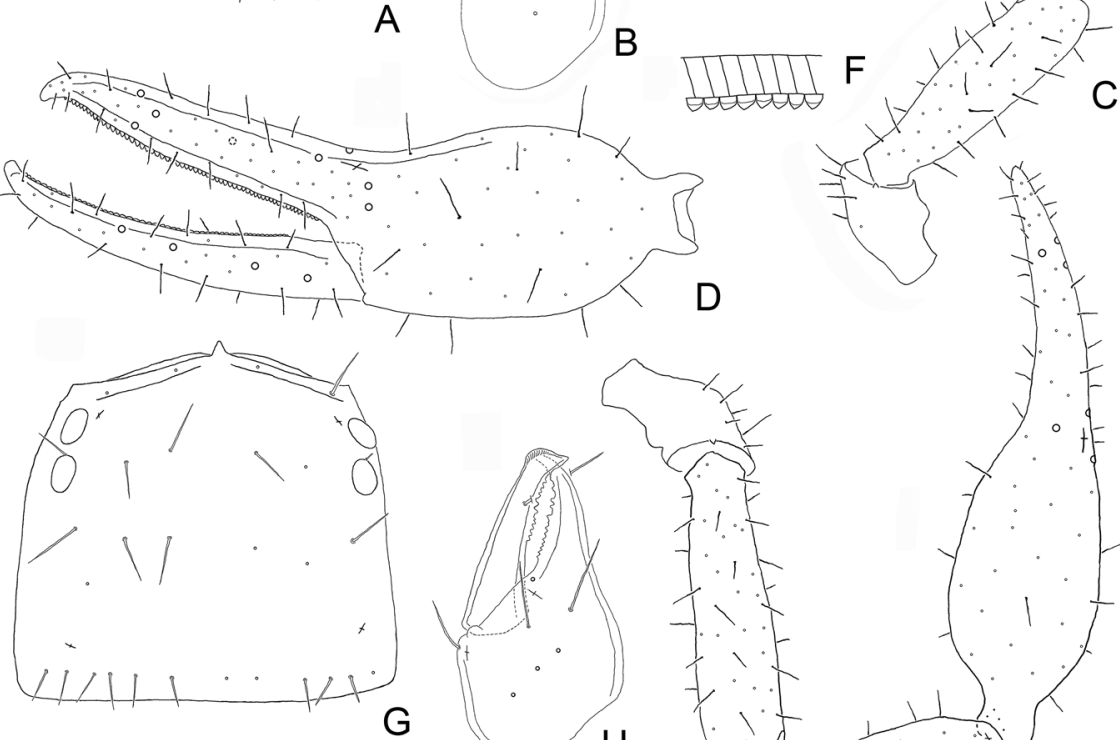

G
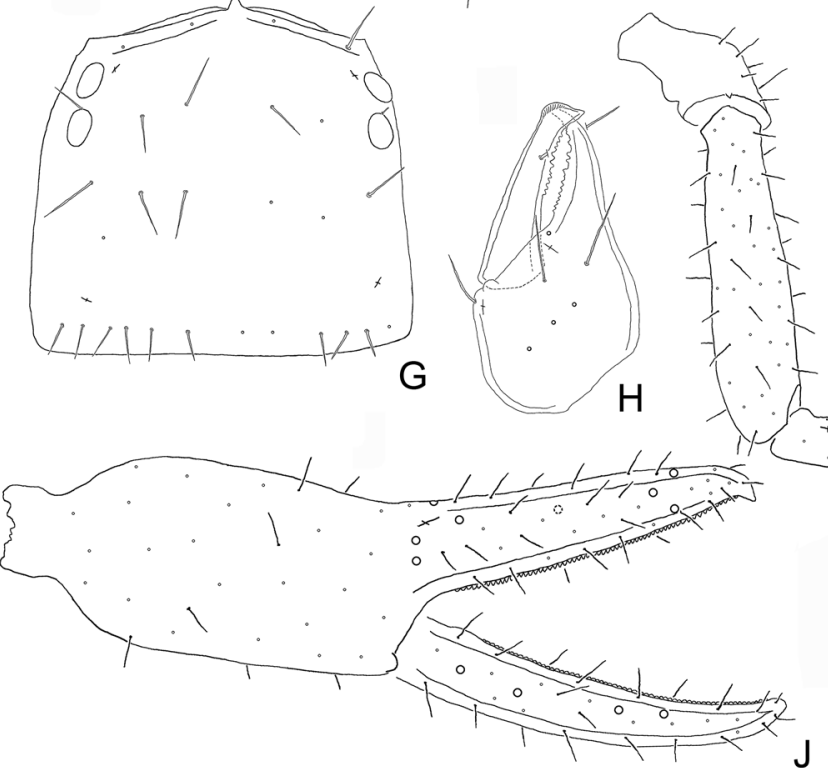

Fig. 4. Neobisium (N.) bosnicum: $\mathrm{A}=$ carapace, male, $\mathrm{B}=$ left chelicera, male, $\mathrm{C}=$ right pedipalp, female, $\mathrm{D}=$ left chela, male, $\mathrm{E}=$ chelal teeth of fixed finger at the level of ist, male, $\mathrm{F}=$ chelal teeth of fixed finger at the level of et, male; G-J = Neobisium (N.) herzegovinense: $G=$ carapace, female, $\mathrm{H}$ = left chelicera, female, $\mathrm{I}=$ right pedipalp, female, $\mathrm{J}$ = right chela, female 
from Greece (MAHNERT 1973). Afterwards no further occurrences of the species were published.

During the present investigation only the adult syntypes were studied. We found greater variability in the setation of the carapace and the tergites, and in the measurement data and proportions than previously mentioned in the literature (BEIER 1939b, 1963). It is worth to mention, that in the sample collected in caves of the Bjelašnica Mts the original description reports 2 males and 3 females; in contrast, we found 3 males and 2 females in the vial.

\section{Neobisium (Neobisium) herzegovinense Beier, 1939}

$$
\text { (Figs 4G-J) }
$$

Type material examined (syntypes): $1 \hat{\delta}, 2$ +, Bosnia and Herzegovina, from higher area of the Volujak Mts, under stones, $2114 \mathrm{~m}$ asl., 09.07.1912 (NHMW-25216).

Description. Medium-sized pseudoscorpion with epigean habitus. Carapace, chelicerae and pedipalps yellowish brown, opisthosoma and legs yellowish. Measurements and ratios of the studied specimens as in Table 3.

Carapace approximately as long as broad, surface smooth (Fig. 4G). Epistome triangular and prominent. Two pair of eyes with lens. One pair of slitlike lyrifissures at anterior and one pair at posterior half of carapace. Preocular setae absent. Setal formula: 4:6:6-8:11-12 (27-30).

Coxal area. Manducatory process with 5-6 setae, rest of pedipalpal coxa with 8-14 setae; pedal coxa I with 8-13 setae; II: 9-12; III: 8-11; IV: 13-17. Anterolateral process of coxa I long, triangular and apically pointed; medial process round and flattened, with denticles.

Opisthosoma with granulostriate pleural membrane. Chaetotaxy of tergites I-X: 8-10:12-14:14-16:16:16-20:16-20:16-18:16-18:16-18:10-12. Segment XI with 16-18 setae, 4-6 of them tactile. Anal cone with 2 ventral and 2 dorsal setae. Male genital region: sternite II with 14 small setae, sternite III with 27 setae, of which 13 along posterior margin. Number of internal setae in male opening and the medial genital sack could not be investigated. Female genital region: sternite II with 10-13 small setae, sternite III with 17-21 small setae in a row. Chaetotaxy of sternites IV-X: 16-24:20-26:20-28:20-27:20-28:19-23:16-18.

Chelicera with 7 setae on hand (Fig. $4 \mathrm{H}$ ). Subgaleal seta $0.62-0.69 \times$ from base of movable finger. Spinneret a flattened hyaline tubercle with 9-13 silk ducts. Fixed finger with 9-16 small and medium-sized teeth, movable finger with 8-10 small and medium-sized teeth. Rallum with 8 blades, two distalmost blades unilaterally pinnate on anterior face. The distalmost blade with enlarged basis and separated from the proceeding one. Serrula exterior with 24-27 blades, serrula interior with 25-27 blades.

Pedipalp (Fig. 4I) surfaces smooth. Trochanter with tubercle. Femur 4.22-4.60, patella 2.65-2.96 times as long as broad. Patella with 2 lyrifissures on basal part and 2 smaller near the articulation with the hand. Pedicel of patella bears 2-4 micropores. Chela (Fig. 4J). Pedicel bears 2-4 dorsal micropores. Chelal fingers approximately as long as hand with pedicel. Fixed chelal finger with 66-71 close-set and pointed teeth of equal length. Movable chelal finger with 57-68 rounded teeth, dental line ending at the level of trichobothrium $b$. Trichobothria of chelal fingers distributed as in Figure 4J. Distance between trichobothria $i b$ and ist approximately as long as between ist and it. 
Legs with smooth surfaces. Claws smooth and simple, arolia shorter than claws on all legs. Subterminal seta of telotarsus IV with two serrate rami. Tactile setae present on tibia, basitarsus and telotarsus of leg IV.

Remarks. The species was desribed by Beier as Neobisium (Neobisium) herzegovinense from one male and two female types, from the Volujak Mts (Bosnia and Herzegovina) (BEIER 1939b). Later BeIER (1963) mentioned N. herzegovinense as a subspecies of $N$. bosnicum as $N$. bosnicum herzegovinense. Since its description no further occurrences of the species were published.

During the present investigation we found greater variability in the setation of the carapace and the tergites, and in the measurement data and proportions than previously mentioned in the literature (BEIER 1939b, 1963).

Considering the important differences between $N$. (N.) bosnicum bosnicum and $N$. (N.) bosnicum herzegovinense in the measurements, ratios and shape of the pedipalps, it is warranted to re-elevate $N$. (N.) bosnicum herzegovinense to full species rank.

\section{DISCUSSION}

Whether the investigated N. polonicum specimens from the NHMW are really syntypes, or not, we suggest $N$. biharicum as a junior subjective synonym of N. polonicum. This is supported by the review of the original descriptions of the two species, and the fact, that in the N. biharicum type material and in the afterwards collected material measurements and morphometrical characteristics - previously used in the literature to distinguish N. polonicum and N. biharicum - showed variation ranges which makes the species differentiation doubtful. Other characteristics, like dentition of the chelae or number of seatae on cheliceral palm proved to be inadequate in the delimitation of the two species in question.

N. polonicum occurs in the Eastern, Northern and Northeastern Carpathians (Poland, Romania, Slovakia, Ukraine) (Rafalski 1937, 1967, Beier 1939a, Hadži 1939, Szent-Ivány 1941, Dumitrescu 1976, Krumpál 1979), in the Western Transylvanian Mts and in transitional areas in Transylvania (Romania) (BeIER 1939a, Novék 2015), and is also known from caves in Dobrogea (Romania) (Ćurčić et al. 1993) and the Pilis Mts (Hungary) (Novák 2013). The data of the species from the Pilis Mts and from Dobrogea suggest that N. polonicum earlier might have a larger occurrence, but now it is a relict form. Regarding to our present knowledge, it seems that - with the exception of Transylvania, the Eastern and Northeastern Carpathians - N. polonicum is restricted to cavernicolous habitats (ĆurČić et al. 1993, NovÁK 2013). 
Due to the lack of data since their original description, the delimitation of many Neobisium species might be problematic, as we have mostly outdated characteristics at our disposal, like the setation of chelicerae and carapace, and extremly narrow ranges of morphometrical values (BEIER 1963). This makes modern redescriptions of numerous Neobisium species not only reasonable, but necessary in the future.

Acknowledgements - The authors would like to thank Dr. Klára Dózsa-Farkas and Tímea Szederjesi for their useful advices. The collecting trips of the first author to Transylvania were supported by the "Campus Hungary Grant" (B1/1F/2270). Special thank belongs to Dr. Gerhard Steiner and the "Ernst Mach Grant - worldwide" scholarship of the OeAD. The authors would like to thank Dr. Wouter Dekonick for informing us about the depository location of the remaining $N$. biharicum types, as well as to all collectors of the investigated material. The manuscript was improved by the comments of Dr. Volker Mahnert and an anonymous referee.

\section{REFERENCES}

Beier, M. (1939a): Pseudoscorpionidea de Roumanie. - Bulletin du Musée Royal d'Histoire Naturelle de Belgique 15(39): 1-21.

Beier, M. (1939b): Die Höhlenpseudoscorpione der Balkanhalbinsel. - Studien aus dem Gebiete der Allgemeinen Karstforschung, der Wissenschaftlichen Höhlenkunde, der Eiszeitforschung und den Nachbargebieten 4(10): 1-83.

Beier, M. (1963): Ordnung Pseudoscorpionidea (Afterskorpione). Bestimmungsbücher zur Bodenfauna Europas, 1. Akademie-Verlag, Berlin, 313 pp.

Chamberlin, J. C. (1931): The arachnid order Chelonethida. - Stanford University Publications. Biological Sciences 7(1): 1-284.

Christophoryová, J., ŠŤáhlavský, F. \& Fedor, P. (2011): An updated identification key to the pseudoscorpions (Arachnida: Pseudoscorpiones) of the Czech Republic and Slovakia. - Zootaxa 2876: 35-48.

ĆurČić, B. P. M., Poinar Jr, G. O. \& Sarbu, S. M. (1993): New and little-known species of Chthoniidae and Neobisiidae (Pseudoscorpiones, Arachnida) from the Movile Cave in southern Dobrogea, Romania. - Bijdragen tot de Dierkunde 63: 221-241.

DeVore-Scribante, A. (1999): Les pseudoscorpions (Arachnida) de la Suisse: étude systématique, faunistique et biogéographique. - Thèse de doctorat en biologie. Université de Genève, Genève, $314 \mathrm{pp}$.

Dumitrescu, D. (1976): Opilionida, Pseudoscorpionida et Acari. In: Contributions a la connaissance de la faune du département Vrancea. - Travaux du Muséum d'Histoire Naturelle Grigore Antipa 17: 273-276.

Hadžı, J. (1939): Pseudoskorpione aus Karpathenrussland. - Věstník Československé Zoologické Společnosti v Praze 6-7: 183-208.

Harvey, M. S. (1992): The phylogeny and classification of the Pseudoscorpionida (Chelicerata: Arachnida). - Invertebrate Taxonomy 6: 1373-1435. https://doi.org/10.1071/IT9921373 
Harvey M. S. (2013): Pseudoscorpions of the World, version 3.0. - Western Australian Museum, Perth. http://museum.wa.gov.au/catalogues-beta/pseudoscorpions (accessed 02 March 2016).

Judson, M. L. I. (2007): A new and endangered species of the pseudoscorpion genus Lagynochthonius from a cave in Vietnam, with notes on chelal morphology and the composition of the Tyrannochthoniini (Arachnida, Chelonethi, Chthoniidae). - Zootaxa 1627: 53-68.

KRumpál, M. (1979): Neobisium polonicum Rafalski, 1937 (Pseudoscorpionidea) nový druh pre faunu ČSSR. - Biologia 34(5): 429-435.

Mahnert, V. (1973): Drei neue Neobisiidae (Arachnida: Pseudoscorpiones) von den Ionischen Inseln (Ueber griechische Pseudoskorpione III). - Berichte des naturwissenschaftlich-medizinischen Vereins Innsbruck 60: 27-39.

Mahnert, V. (2004): Die Pseudoskorpione Österreichs (Arachnida, Pseudoscorpiones). Denisia 12, N.S. 14: 459-471.

NovÁk, J. (2013): First records of Larca lata (Hansen, 1884) and Neobisium biharicum Beier 1939 from Hungary. - Opuscula Zoologica 44(2): 161-166.

NovÁk, J. (2014): Notes on two species of the cavernicolous subgenus Neobisium (Blothrus) Schiödte, 1847 (Arachnida: Pseudoscorpiones) from Transylvania (Romania), with a key to the species of the Carpathian Mountains. - Zootaxa 3796(2): 394-400. https://doi.org/10.11646/zootaxa.3796.2.11

Novák, J. (2015): New data on the pseudoscorpion fauna of Sălaj County, Romania (Arachnida: Pseudoscorpiones). - Studia Universitatis "Vasile Goldiş" 25(3): 203-205.

RAFAlSKI, J. (1937): Neobisium (Neobisium) polonicum nov. spec, Nowy gatunek zaleszczotka (Pseudoscorpionidae). - Poznanskie Towarzystwo Przyjaciól Nauk, Prace Komisji Matematyczno-przyrodniczej, Seria B. Tom VIII. zeszyt 5: 1-14.

Rafalski, J. (1967): Zaleszczotki. Pseudoscorpionidea. Pp 1-34. In: Katalog Fauny Polski 32(1). - Państwowe Wydawnictwo Naukowe, Warszawa.

Szent-IvánY, J. (1941): Neue Angaben zur Verbreitung der Pseudoscorpione im Karpatenbecken. - Fragmenta Faunistica Hungarica 4 (1-4): 85-90.

Received May 17, 2016, accepted September 30, 2016, published July 21, 2017 